\title{
Konstruksi Forecasting System Multi-Model untuk pemodelan matematika pada peramalan Indeks Pembangunan Manusia Provinsi Nusa Tenggara Barat
}

\author{
Lalu Sucipto a, Syaharuddin Syaharuddin ${ }^{b}$ \\ a Tadris Matematika, Universitas Islam Negeri Mataram, Mataram, Indonesia \\ ${ }^{b}$ Pendidikan Matematika, Universitas Muhammadiyah Mataram, Mataram, Indonesia \\ email:aciptobajok@gmail.com,bsyaharuddin@ummat.ac.id
}

\begin{tabular}{l}
\hline I N F O A R T I K E L \\
\hline Sejarah artikel: \\
Menerima 11 Agustus 2018 \\
Revisi 21 Agustus 2018 \\
Diterima 2 September 2018 \\
Online 2 September 2018 \\
\hline Kata kunci: \\
Exponential Smoothing \\
Forecasting System Multi- \\
Model \\
Indeks Pembangunan \\
Manusia \\
Nusa Tenggara Barat \\
pemodelan matematika \\
\hline Keywords: \\
Exponential Smoothing \\
Forecasting System Multi- \\
Model \\
mathematical model \\
Human Development Index \\
West Nusa Tenggara \\
\hline Style APA dalam mensitasi \\
artikel ini: \\
Sucipto, L., \& Syaharuddin, \\
S. (2018). Konstruksi \\
Forecasting System Multi- \\
Model untuk pemodelan \\
matematika pada peramalan \\
Indeks Pembangunan \\
Manusia Provinsi Nusa \\
Tenggara Barat. Register: \\
Jurnal Ilmiah Teknologi Sistem \\
Informasi, 4(2), 114-123. \\
\end{tabular}

\begin{abstract}
ABSTRAK
Penelitian ini bertujuan untuk mengembangkan produk Forecasting System MultiModel (FSM) guna menentukan metode terbaik dalam sistem peramalan (forecast) dengan mengkonstruksi beberapa metode dalam bentuk Graphical User Interface (GUI) Matlab dengan menghitung semua indikator tingkat akurasi guna menemukan model matematika terbaik dari data time series pada periode tertentu. Pada tahap simulasi, tim peneliti menggunakan data Indeks Pembangunan Manusia (IPM) Provinsi Nusa Tenggara Barat (NTB) tahun 2010-2017 guna memprediksi IPM NTB tahun 2018. Adapun metode yang diuji adalah Moving Average (SMA, WMA dan EMA), Exponential Smoothing Method (SES, Brown, Holt, dan Winter), Naive Method, Interpolation Method (Newton Gregory), dan Artificial Neural Network (Back Propagation). Kemudian model dievaluasi untuk melihat tingkat akurasi masing-masing metode berdasarkan nilai MAD, MSE, dan MAPE. Berdasarkan hasil simulasi data dari 10 metode yang diuji diketahui bahwa metode Holt paling akurat dengan hasil prediksi tahun 2018 sebesar 67,45 dengan MAD, MSE, dan MAPE berturut-turut sebesar 0,22654; 0,075955 dan 0,34829.
\end{abstract}

\begin{abstract}
The purpose of this research is to develop a product was called Forecasting System MultiModel (FSM) to determine the best method in the forecasting system by constructing several methods in the form of Graphical User Interface (GUI) Matlab. It was done by all indicator accuration to find the best mathematical model of time series data in a certain period. In the simulation phase, this research used the Human Development Index (HDI) data of West Nusa Tenggara (NTB) Province in 2010 - 2017 to predict the HDI data of NTB in 2018. The methods tested were Moving Average (SMA, WMA and EMA), Exponential Smoothing Method (SES, Brown, Holt, and Winter), Naive Method, Interpolation Method (Newton Gregory), and Artificial Neural Network (Back Propagation). Then the models/methods were evaluated to see the level of accuracy of each method based on the value of MAD, MSE, and MAPE. Based on data simulation result from 10 tested method known that Holt method is most accurate with prediction result of 2018 equal to 67,45 with MAD, MSE, and MAPE respectively equal to $0.22654,0.075955$ and 0.34829 .
\end{abstract}

(c) 2018 Register: Jurnal IImiah Teknologi Sistem Informasi. Semua hak cipta dilindungi undang-undang.

\section{Pendahuluan}

Peramalan (forecasting) adalah kegiatan mengestimasi apa yang akan terjadi pada masa yang akan datang. Peramalan diperlukan karena adanya kesenjangan waktu (timelag) antara kesadaran dibutuhkannya suatu kebijakan baru dengan waktu pelaksanaan kebijakan tersebut. Jika perbedaan waktu tersebut panjang, maka peran peramalan begitu penting dan sangat dibutuhkan terutama dalam 
penentuan waktu kapan akan terjadinya sesuatu, sehingga dapat dipersiapkan tindakan yang perlu dilakukan. Metode peramalan akan membantu dalam mengadakan pendekatan analisa terhadap tingkah laku atau pola dari data yang lalu, sehingga dapat memberikan cara pemikiran, pengerjaan dan pemecahan yang sistematis dan pragmatis, serta memberikan tingkat keyakinan yang lebih atas ketepatan hasil ramalan yang dibuat (Sudarsono, 2016). Umumnya peramalan banyak dilakukan pada data time series yang dikelola oleh Badan Pusat Statistika (BPS) baik kabupaten, provinsi, maupun nasional karena berdampak pada penentuan kebijakan oleh pemerintah.

Penentuan sebuah kebijakan tentu berlandaskan data yang terjadi di lapangan. Kebijakan tersebut tidak lepas dari pola sebaran data yang saling berkaitan seperti data kependudukan, kesehatan, pendidikan, dan data Indeks Pembangunan Manusia (IPM) sering digunakan sebagai patokan dalam konstruksi kebijakan di tingkat pemerintah. Oleh sebab itu, data-data ini perlu dikonstruksi menjadi informasi penting berupa hasil analisa dan model matematika sebagai dasar dalam pengambilan kebijakan tersebut.

Dewasa ini, perkembangan berbagai macam metode peramalan disajikan dengan algoritma yang mampu mempermudah para pengguna dalam mengoperasikannya. Namun tidak semua metode mampu digunakan dalam semua situasi khususnya yang berkaitan dengan data time series. Beberapa metode yang sering digunakan dalam proses peramalan data time series antara lain Moving Average, Exponential Smoothing Method, Naive Method, Interpolation Method dan Jaringan Syaraf Tiruan (JST) atau Artificial Neural Network (ANN) tipe Back Propagation (Suryani \& Wahono, 2015) (Surihadi, 2009). Sehingga untuk mengantisipasi ketidakcocokan tersebut, setiap proses ditunjukkan dengan tingkat akurasi masing-masing metode seperti Mean Absolute Deviation (MAD), Mean Square Error (MSE), dan Mean Absolute Percentage Error (MAPE). Metode dengan tingkat error paling kecil atau tingkat akurasi paling tinggi disebut metode terbaik pada kasus yang disajikan. Perkembangan teknologi dan sistem informasi sudah sangat maju, berbagai software dikembangkan untuk mempermudah peneliti dalam melakukan simulasi seperti SPSS, Minitab, Limo, QM for Windows, Matlab, dan lain-lain (Guangpu \& Yuchun, 2012) (Ayub, Sembok, \& Luan, 2008). Namun setiap software memiliki kelebihan dan kekurangan masing-masing. Kemudian di satu sisi, kebanyakan software tersebut hanya menampilkan satu indikator untuk ukuran tingkat akurasi (Irawan, Syaharuddin, Utomo, \& Rukmi, 2013). Sementara data inputan memiliki karakteristik dan trend yang berbeda-beda, sehingga membutuhkan indikator tingkat akurasi yang mencakup semua kemungkinan kejadian (Andriani, Silitonga, \& Wanto, 2018). Oleh sebab itulah, pentingnya kegiatan ilmiah untuk mengkonstruksi sebuah Graphical User Interface (GUI) berbasis Matlab dengan menampilkan semua indikator tingkat akurasi tersebut, sehingga terlihat jelas metode yang terbaik untuk dirujuk sebagai model matematika yang berimplikasi pada diperolehnya hasil prediksi atau peramalan yang baik dalam jangka panjang.

\section{State of the Art}

Adapun beberapa penelitian yang relevan dengan penelitian ini sebagai berikut:

1. Suryani dan Wahono (2015) mengusulkan penelitian tentang penerapan Exponential Smoothing untuk transformasi data dalam meningkatkan akurasi Jaringan Syaraf Tiruan (JST) atau Neural Network (NN) pada prediksi harga emas. Dalam penelitian tersebut dijelaskan bahwa metode Exponential Smoothing digunakan untuk melakukan transformasi data guna meningkatkan kualitas data, sehingga dapat meningkatkan akurasi prediksi pada NN dan diperoleh kesimpulan dari eksperimen yang dilakukan adalah bahwa prediksi harga emas menggunakan $\mathrm{NN}$ dan Exponential Smoothing lebih akurat dibanding metode individual NN.

2. Sudarsono (2016) mengusulkan penelitian tentang penerapan JST untuk memprediksi laju pertumbuhan penduduk menggunakan metode Bacpropagation di Kota Bengkulu), dalam penelitian ini jaringan terbentuk dilakukan training dari data yang telah dikelompokkan tersebut. Pengujiannya dilakukan dengan perangkat lunak Matlab. Percobaan yang dilakukan dengan arsitektur jaringan yang terdiri dari unit masukan, unit layer tersembunyi dan unit keluarannya. Hasil yang didapat dari pengujian tersebut adalah niali performance dan epochs setiap arsitektur tidak sama. Hasil pengujiannya ditampilkan dalam bentuk grafik perbandingan nilai target dengan nilai pelatihan. 
3. Suhaedi, Febriana, Syaharuddin, dan Negara (2017) mengusulkan penelitian tentang ANN Back Propagation untuk peramalan dan simulasi data hidroklimatologi. Dalam penelitian tersebut dijelaskan bahwa Back Propagation mampu memberikan hasil yang baik dalam proses peramalan data hidroklimatologi dengan tingkat akurasi mencapai 99,76\% dan persentase error mencapai $1,12 \%$. Simulasi dilakukan menggunakan software bantuan GUI Matlab.

Berdasarkan beberapa penelitian di atas, diperoleh informasi bahwa Matlab sangat baik dijadikan objek pengembangan dan simulasi beberapa metode komputasi. Sehingga dalam hal ini, penelitian akan diusulkan pengembangan produk Forecasting System Multi-Model (FSM). FSM adalah sebuah aplikasi baru yang dikembangkan menggunakan GUI Matlab dengan menampilkan metode Moving Average (SMA, WMA dan EMA), Exponential Smoothing Method (SES, Brown, Holt, dan Winter), Naive Method, Interpolation Method (Newton Gregory), dan Artificial Neural Network (Back Propagation) dalam satu GUI, sehingga mempermudah dalam simulasi dan melihat output tabel dan grafik tanpa harus melakukan inputan yang berulang-ulang.

\section{Metode Penelitian}

\subsection{Model pengembangan}

Jenis penelitian ini merupakan penelitian pengembangan atau Research and development (R\&D). Model pengembangan yang digunakan dalam penelitian ini adalah 4-D (Define, Design, Develop, and Disemination) yang dikembangkan oleh (Thiagarajan, Semmel, \& Semmel, 1974), Semmel dan Semmel yang dimodifikasi. Model pengembangan yang telah dimodifikasi tersebut ditunjukkan pada Gambar 1.

\begin{tabular}{|ccc|}
\hline Perumusan Garis Besar Aplikasi & \multicolumn{2}{c|}{ Defune } \\
& Donstruksi Flow Chart \& M-Function & \\
Prototype Awal & & Training Data \\
Validasi Tim Pakar & Development & Uji Coba Produk \\
& & \\
Revisi Produk & Dissemination & Final Produk \\
\hline
\end{tabular}

Gambar 1. Model pengembangan (Syaharuddin, Negara, Mandailina, \& Sucipto, 2017)

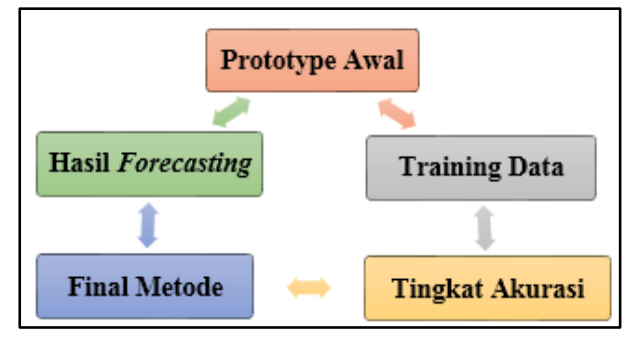

Gambar 2. Alur forecasting (Irawan, Syaharuddin, Utomo, \& Rukmi, 2013)

Tabel 1. Data IPM NTB Tahun 2010-2017

\begin{tabular}{cccc}
\hline No & Tahun & Data & Peningkatan \\
\hline 1. & 2010 & 61.16 & - \\
2. & 2011 & 62.14 & $1.60 \%$ \\
3. & 2012 & 62.98 & $1.35 \%$ \\
4. & 2013 & 63.79 & $1.29 \%$ \\
5. & 2014 & 64.31 & $0.82 \%$ \\
6. & 2015 & 65.19 & $1.37 \%$ \\
7. & 2016 & 65.81 & $0.95 \%$
\end{tabular}




8. $2017 \quad 66.58 \quad 1.17 \%$

Berdasarkan Gambar 2 dapat dilihat, bahwa pengembangan FSM melalui 5 tahap utama yakni:

1. Pengembangan prototype awal: Semua metode disusun dalam satu GUI, kemudian dilakukan uji validasi ahli dengan menggunakan angket dan diskusi ilmiah agar diperoleh hasil yang valid,

2. Training data: Pada tahap ini dilakukan training data menggunakan data IPM NTB sesuai Tabel 1 dengan melihat tingkat akurasi masing-masing metode,

3. Tingkat akurasi diperoleh dari hasil training data dengan melihat MAD, MSE, dan MAPE yang ditampilkan pada tabel atau grafik hasil simulasi,

4. Final metode: Pada tahap ini ditentukan metode terbaik dengan melihat MAD, MSE, dan MAPE paling kecil, kemudian ditentukan model matematika menggunakan metode Newton Gregory derajat 7.

\subsection{Prosedur pengembangan produk}

Pada penelitian ini prosedur pengembangan produk dilakukan dengan beberapa tahapan, yaitu:

1. Desain Produk: Pada tahap ini dibangun desain produk yang dikembangkan. Desain yang digunakan mengikuti alur model pengembangan 4-D. Pada tahap ini pula penelitian dibangun rancangan awal (Prototype 1) produk dengan training data buatan,

2. Validasi Ahli: Pada tahap ini dilakukan validasi tim pakar, yakni (1) Pakar desain GUI, (2) Pakar komputasi dan (3) Pakar forecasting dengan menggunakan angket penilaian validator. Dalam hal ini tim peneliti akan berkolaborasi dengan tim Laboran Pendidikan Matematika UIN Mataram. Hasil validasi kemudian direvisi sehingga menciptakan Prototype 2.

3. Uji Coba Produk: Prototype 2 kemudian dilakukan uji coba produk dengan silmulasi data Indeks Pembangunan Manusia (IPM) NTB. Revisi uji coba ini diperoleh Prototype 3.

4. Analisa Data: Proses analisis data validitas produk yang dikembangkan dilakukan dengan rumus sebagai berikut (Sugiono, 2016) (Suhaedi, Febriana, Syaharuddin, \& Negara, 2017),

$$
R=\frac{\sum_{i=1}^{n} V_{i}}{n}
$$

Pada Persamaan $1, R$ merupakan rata-rata skor dari semua validator yang dalam penelitian ini menggunakan 3 validator, $V_{i}$ adalah rata-rata skor tiap validator, sedangkan $n$ adalah jumlah validator. Kemudian berdasarkan nilai $R$ dapat ditentukan kategori valid tau tidak valid dari produk yang sedang dikembangkan berdasarkan Tabel 2 .

Tabel 2. Interval Nilai Validitas Produk

\begin{tabular}{ccl}
\hline No & Interval & Tingkat Validitas \\
\hline 1. & $R=5$ & Sangat valid \\
2. & $4 \leq R<5$ & Valid \\
3. & $3 \leq R<4$ & Cukup valid \\
4. & $2 \leq R<3$ & Kurang valid \\
5. & $1 \leq R<2$ & Tidak valid \\
\hline
\end{tabular}

5. Final Produk: Pada tahap ini dilakukan pengemasan aplikasi yang sudah direvisi (Prototype 4) dalam bentuk Project Application. Kemudian data hasil peramalan dideskripsikan dari segi hasil dan tingkat akurasi.

\section{Hasil dan Pembahasan}

\subsection{Hasil validasi ahli}

Validasi ahli dilakukan setelah desain awal atau Prototype 1 selesai. Validasi ahli dilakukan untuk meminta saran atau masukan terkait 3 aspek yakni desain GUI, komputasi dan forecasting. Adapun hasil validasi sesuai Tabel 3.

Tabel 3. Daftar nama validator Prototype 1

\begin{tabular}{ccccc}
\hline No & Validator & Aspek & Rerata & Kategori \\
\hline 1. & Validator 1 & Peramalan & 3.400 & Cukup Valid
\end{tabular}




\begin{tabular}{|c|c|c|c|c|}
\hline 2. & Validator 2 & Pemrograman & 4.000 & Valid \\
\hline 3. & Validator 3 & Desain & 3.600 & Cukup Valid \\
\hline \multicolumn{3}{|c|}{ Kesi } & 3.667 & Cukup Valid \\
\hline
\end{tabular}

Berdasarkan Tabel 3 diperoleh rata-rata hasil penilaian ahli adalah 3,667 yang berarti cukup valid. Dari hasil validasi ini maka dilanjutkan ke uji coba produk dengan model training data. Beberapa revisi berdasarkan masukan dari tim pakar terkait:

a. Keteraturan tombol (load data, hitung, hapus, simpan, dan keluar)

b. Maximize system dan minimize system ditampilkan.

c. Ukuran ketebalan grafik, termasuk pelabelan sumbu $X$ dan sumbu $Y$ grafik hasil forecast dan aktualnya.

d. Kesalahan perhitungan pada hasil peramalan termasuk tingkat akurasi (MAD, MSE, dan MAPE)

Seluruh saran untuk revisi dari tim pakar sudah dilakukan sehingga diperoleh desain GUI FSM awal seperti pada Gambar 3.

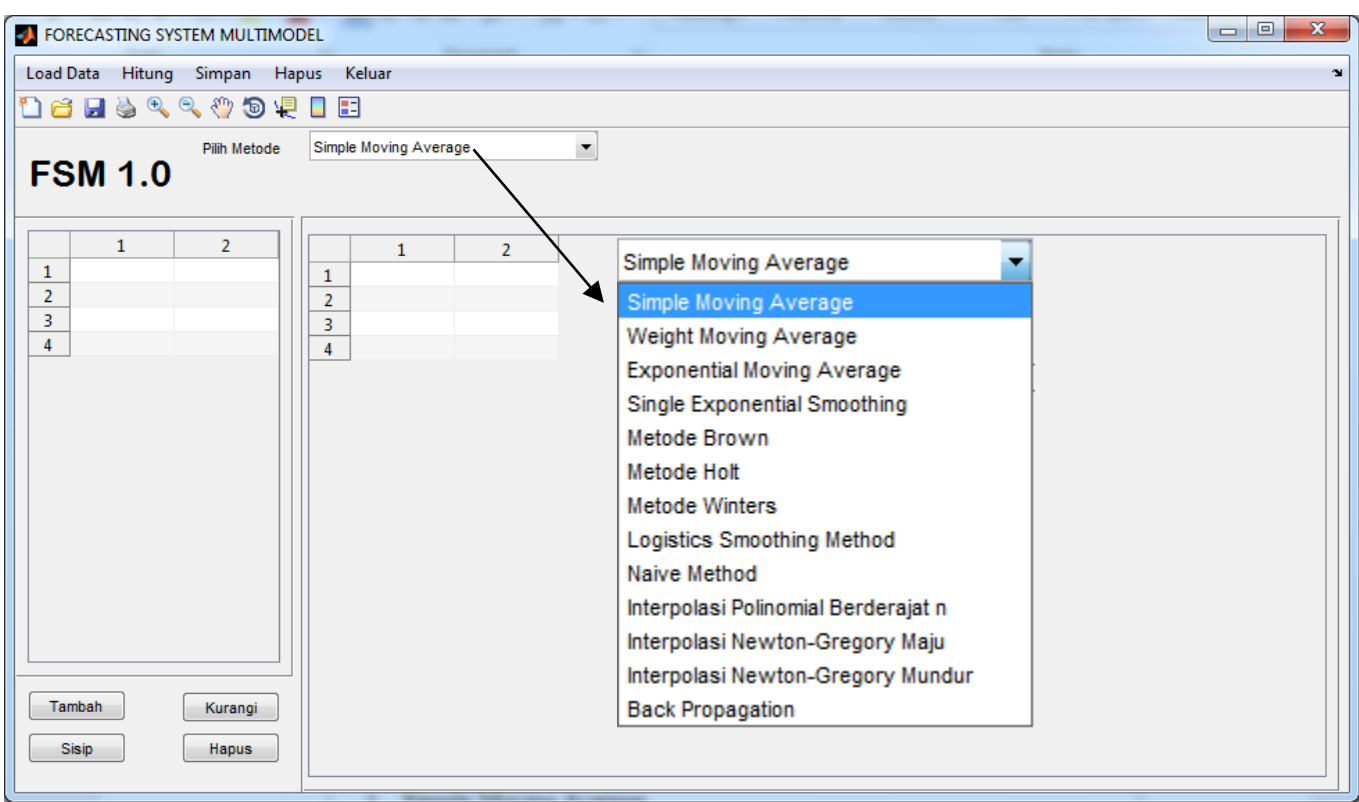

Gambar 3. Desain GUI FSM 1.0 


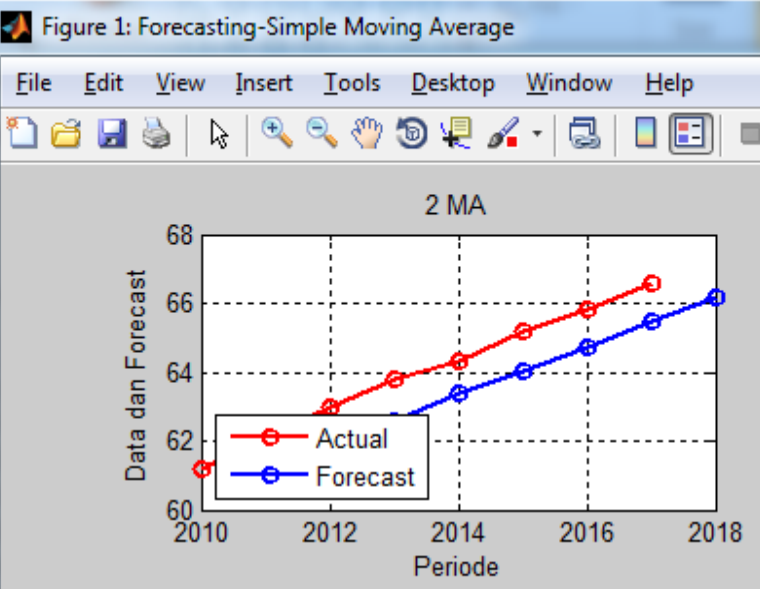

\begin{tabular}{l|l|l|l|l|l|l|}
\hline & 口 & 回 \\
\hline
\end{tabular}
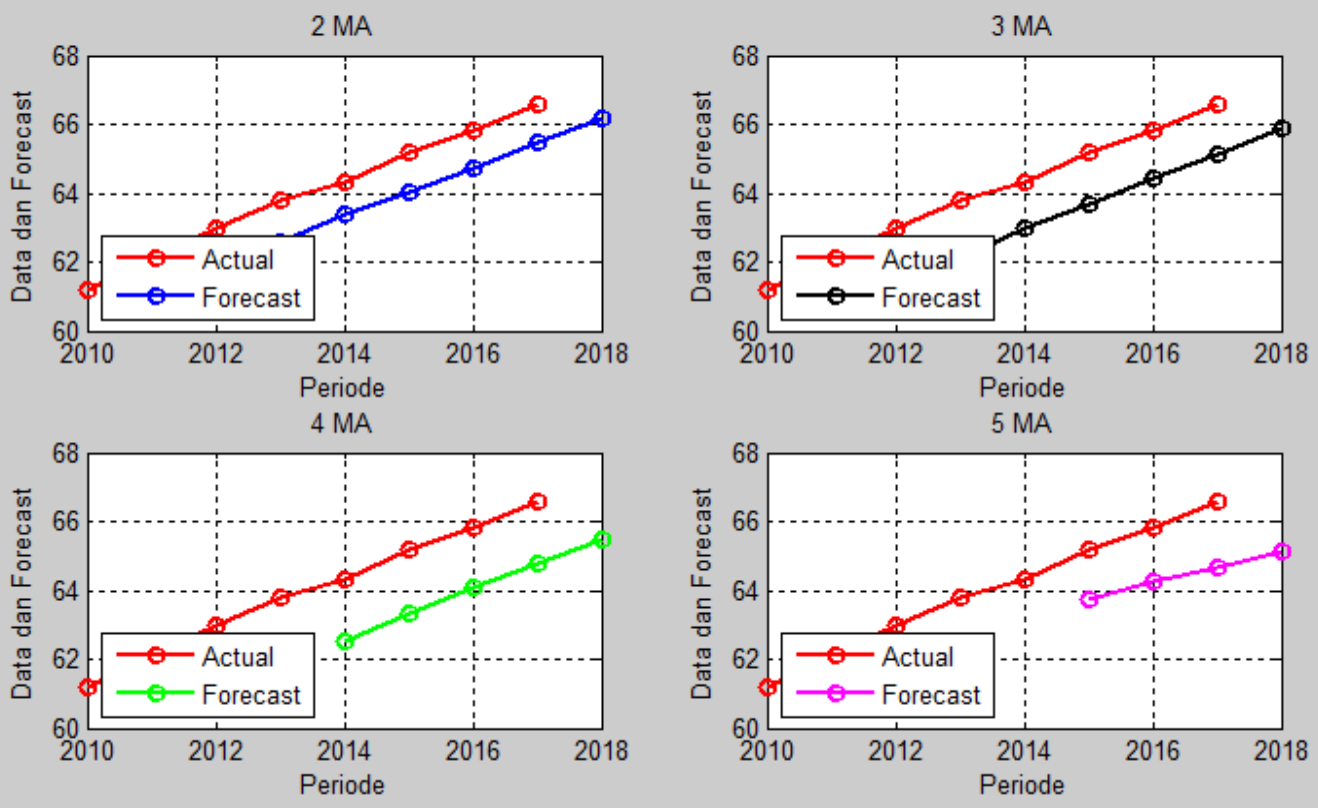

Gambar 4. Hasil simulasi metode SMA

\subsection{Hasil simulasi}

Berikut adalah hasil pengujian berdasarkan beberapa metode yang diusulkan:

1. Simple Moving Average (SMA)

Pada simulasi SMA Gambar 4, pengujian dilakukan 4 kali percobaan (simulasi), yakni menggunakan tipe 2MA, 3MA, 4MA, dan 5MA. Tipe MA ditentukan berdasarkan rata-rata langkah perpindahan data, misalnya 2MA dimaksudkan bahwa hasil forecast pada langkah selanjutnya diperoleh dari rata-rata dua data sebelumnya, begitu juga 3MA dimaksudkan bahwa hasil forecast pada langkah selanjutnya diperoleh dari rata-rata tiga data sebelumnya, dan seterusnya untuk 4MA dan 5MA.

Berdasarkan hasil simulasi baik tabel maupun grafik diketahui bahwa Moving Average (MA) yang paling baik hasilnya dengan MAPE paling rendah adalah MA tipe 2 (2MA) yakni setiap langkah menentukan rata-rata dua data sebelumnya atau yakni sebesar 1,7743 dengan hasil prediksi tahun 2018 sebesar 66.195. Sedangkan hasil MAPE tipe yang lain yakni 3MA sebesar 2,2708; 4MA sebesar 2,7594; dan 5MA sebesar 2,4738.

2. Weight Moving Average (WMA)

Pada metode Weight Moving Average (WMA), pengujian dilakukan dengan menggunakan 3 tipe yakni 2WMA, 3WMA, dan 4WMA. WMA hampir sama dengan SMA, dimana perhitungan hasil forecast, pada langkah selanjutnya diperoleh dari rata-rata data sebelumnya tergantung tipe yang digunakan, hanya perbedaannya terletak pada penambahan variabel bobot yang diberikan, karena SMA tidak adanya bobot, sedangkan WMA diberikan bobot pada setiap data. Kemudian bobot yang digunakan untuk simulasi data menggunakan metode WMA sesuai Tabel 4.

\begin{tabular}{ccc}
\multicolumn{2}{c}{ Tabel } & B. Bobot masing-masing metode WMA \\
\hline No & Tipe Metode WMA & Pembobotan \\
\hline 1. & 2WMA & Bobot $1=0.4$ \\
& & Bobot $2=0.6$ \\
2. & 3WMA & Bobot $1=0.2$ \\
& & Bobot $2=0.3$ \\
& & Bobot $3=0.5$ \\
3. & 4WMA & Bobot $1=0.1$ \\
& & Bobot $2=0.2$ \\
\hline
\end{tabular}


Bobot $3=0.3$

Bobot $4=0.4$

Berdasarkan hasil simulasi data diperoleh hasil peramalan terbaik pada tahun 2018 menggunakan tipe 2WMA sebesar 66,272 dengan MAD, MSE, dan MAPE berturut-turut sebesar 1,$05 ; 1,1181$ dan 1,6233 .

3. Exponential Moving Average (EMA)

Pada metode ini dilakukan simulasi dengan 4 jenis moving, yakni 2EMA, 3EMA, 4EMA, dan 5 EMA dengan masing-masing alfa sebesar 0,2. Berdasarkan hasil simulasi data, diperoleh hasil peramalan terbaik pada tahun 2018 menggunakan tipe 5EMA sebesar 64,5004 dengan MAD, MSE, dan MAPE berturut-turut sebesar 1,5177; 2,9339 dan 2,3301.

4. Single Exponential Smoothing (SES)

Berdasarkan hasil simulasi data diperoleh informasi bahwa prediksi tahun 2018 sebesar 64,2125 dengan MAD, MSE, dan MAPE berturut-turut sebesar 2,1804; 5,1667 dan 3,3652.

5. Metode Brown

Pada metode ini, tim peneliti melakukan simulasi metode Exponential Smoothing Brown (ESB) dengan alfa sebesar 0,2 dan periode prediksi 1. Berdasarkan hasil simulasi data diperoleh informasi bahwa prediksi tahun 2018 sebesar 66,1376 dengan MAD, MSE, dan MAPE berturutturut sebesar 1,2472; 1,7924 dan 1,9284.

6. Metode Holt

Simulasi menggunakan metode Holt dilakukan dengan nilai parameter alfa sebesar 0,2; beta sebesar 0,8; dan periode prediksi sebesar 1 . Berdasarkan hasil simulasi data diperoleh informasi bahwa prediksi tahun 2018 sebesar 67,4516 dengan MAD, MSE, dan MAPE berturut-turut sebesar 0,$22654 ; 0,075955$ dan 0,34829 .

7. Metode Winters

Pada simulasi data menggunakan metode Winters, pengujian ditetapkan nilai parameter seperti alfa sebesar 0,2; beta sebesar 0,3; gama sebesar 0,5; quarterly sebesar 4 dan periode prediksi sebesar 1. Berdasarkan hasil simulasi data diperoleh informasi bahwa prediksi tahun 2018 sebesar 71,8755 dengan MAD, MSE, dan MAPE berturut-turut sebesar 5,6784; 35,406 dan 8,5898.

8. Metode Naïve

Berdasarkan hasil simulasi data diperoleh informasi bahwa prediksi tahun 2018 sebesar 66,58 dengan MAD, MSE, dan MAPE berturut-turut sebesar 0,77429; 0,6206 dan 1,2054.

9. JST Back Propagation

Pada simulasi menggunakan JST Backpropagation, pengujian digunakan struktur JST sesuai Tabel 5.

Tabel 5. Atribut dan parameter JST Backpropagation

\begin{tabular}{crl}
\hline No & \multicolumn{1}{c}{ Atribut } & Parameter \\
\hline 1. & Fungsi Aktivasi & Logsig \\
& Jumlah Neuron \\
2. & a. Input layer & 8 \\
& b. Hidden layer 1 & 2 \\
& c. Hidden layer 2 & 2 \\
3. & Metode Training & 1 \\
& Paramater Akurasi & Trainrp \\
4. & a. Maks Epoch & 10.000 \\
& b. Goal & 0,0001 \\
& c. Learning Rate & 100 \\
& d. Show Step & 100 \\
\hline
\end{tabular}



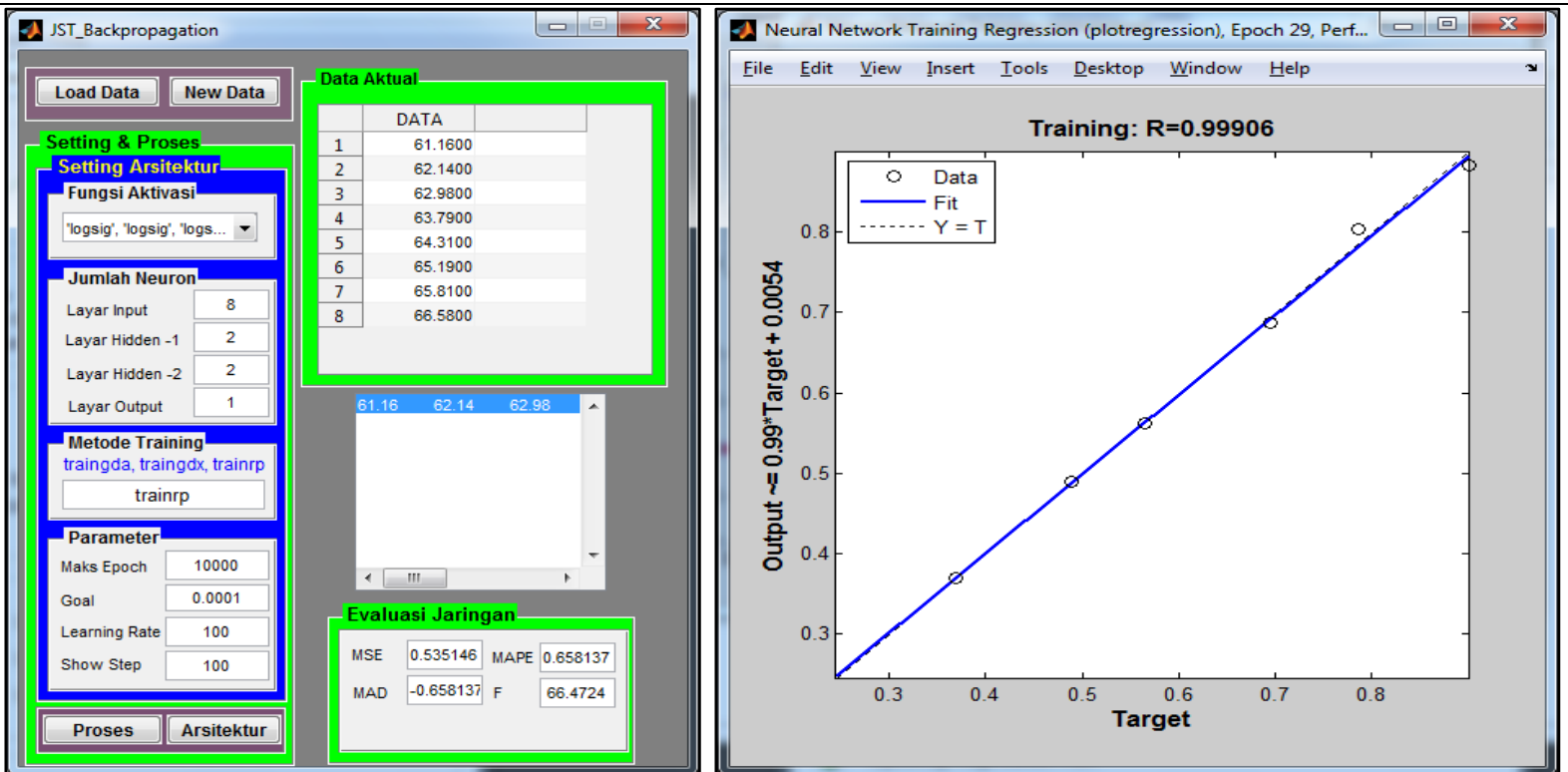

Gambar 5. Hasil simulasi JST Back Propagation

Berdasarkan hasil simulasi pada Gambar 5 diperoleh informasi bahwa prediksi tahun 2018 sebesar 66,4724 dengan MAD, MSE, dan MAPE berturut-turut sebesar 0,6581; 0,5351 dan 0,6581. Berdasarkan hasil simulasi 9 metode, maka dapat dirangkum sesuai Tabel 6.

Berdasarkan Tabel 6, maka diperoleh metode yang paling baik untuk prediksi data IPM NTB adalah metode Exponential Smooting Holt dengan hasil prediksi tahun 2018 sebesar 67,45 dengan MAD, MSE, dan MAPE paling kecil yakni sebesar 0,2265; 0,0759 dan 0,3483. Adapun tampilan grafik antara data aktual dan prediksi sesuai Gambar 6. Berdasarkan Tabel 6, jika diurutkan metode dengan tingkat error paling kecil, maka diperoleh susunan mulai metode Holt, JST Backpropagation, metode Naïve, 2WMA, 2SMA, 3WMA, 3SMA, 5EMA, 5SMA, 4EMA, 4SMA, 3EMA, 2EMA, SES dan metode Winters.

Metode Holt merupakan salah satu pengembangan dari metode exponential smoothing dengan menambah bobot alfa dan beta, di mana nilai keduanya tidak melebihi 1 . Dalam simulasi ini, tim menggunakan nilai alfa sebesar 0,2 dan beta sebesar 0,8 . Sedangkan untuk periode prediksi adalah 1 tahun setelahnya yaitu 2018. Dalam hal ini, peneliti lain bisa melakukan prediksi untuk $n$ tahun tergantung kebutuhan, namun hal ini akan berpengaruh pada tingkat akurasi hasil prediksi. Jika merujuk pada Tabel 1, maka tingkat peningkatan IPM NTB tahun 2018 sebesar 1,30\%. Kemudian jika dilakukan konstruksi model matematika menggunakan interpolasi Newton-Gregory derajat 7, di mana $x$ menyatakan data forecast, $f_{0}$ menyatakan selisih data ke- $n$ dengan data sebelumnya $\left(x_{n}-x_{n-1}\right)$, dan $P_{n}(x)$ menyatakan persamaan model matematika, maka diperoleh Persamaan 2 ,

$$
\begin{aligned}
P_{n}(x)= & \frac{f_{0}}{0 !}+\frac{s \Delta f_{0}}{1 !}+\frac{s(s-1) \Delta^{2} f_{0}}{2 !}+\frac{s(s-1)(s-2) \Delta^{3} f_{0}}{3 !}+\ldots+\frac{s(s-1)(s-2) . .(s-6) \Delta^{7} f_{0}}{3 !} \\
P_{7}(x)= & \frac{61.16}{0 !}+\frac{0.98 x}{1 !}-\frac{0.14 x(x-1)}{2 !}+\frac{0.11 x(x-1)(x-2)}{3 !}-\frac{0.37 x(x-1)(x-2)(x-3)}{4 !} \\
& +\frac{1.28 x(x-1)(x-2)(x-3)(x-4)}{5 !}-\frac{3.46 x(x-1)(x-2)(x-3)(x-4)(x-5)}{6 !} \\
& +\frac{7.94 x(x-1)(x-2)(x-3)(x-4)(x-5)(x-6)}{7 !} \\
P_{7}(x)= & 0.0016 \mathrm{x}^{7}-0.038 \mathrm{x}^{6}+0.358 \mathrm{x}^{5}-1.689 \mathrm{x}^{4}+4.124 \mathrm{x}^{3}-4.924 \mathrm{x}^{2}+3.146 \mathrm{x}+61.16
\end{aligned}
$$

berdasarkan persamaan $P_{7}(x)$ menggunakan Matlab, diperoleh grafik sesuai Gambar 7 .

Tabel 6. Hasil prediksi masing-masing metode

\begin{tabular}{cccccc}
\hline No & Atribut & Forecast & MAD & MSE & MAPE \\
\hline 1. & Simple Moving Average & & 1,1275 & 1,2878 & 1,7433 \\
& a. 2SMA & 66,19 & 1,478 & 2,1998 & 2,2708 \\
& b. 3SMA & 65,86 & 1,8063 & 3,2652 & 2,7594
\end{tabular}




\section{c. $4 \mathrm{SMA}$ \\ d. 5SMA}

2. Weight Moving Average
a. 2WMA
b. 3WMA
c. 4WMA

3. Exponential Moving Average
a. 2EMA
b. 3EMA
c. 4EMA
d. 5EMA

4. Single Exponential Smoothing

5. Metode Brown

6. Metode Holt

7. Metode Winters

8. Metode Naïve

9. Back Propagation
65,47

65,14

$\begin{array}{llll}66,27 & 1,05 & 1,1181 & 1,6233 \\ 66,07 & 1,2482 & 1,5712 & 1,9175 \\ 65,84 & 1,4295 & 2,0475 & 2,183 \\ & & & \\ 64,29 & 1,9591 & 4,3833 & 3,0181 \\ 64,37 & 1,7589 & 3,7749 & 2,704 \\ 64,44 & 1,5976 & 3,2822 & 2,4522 \\ 64,50 & 1,5177 & 2,9339 & 2,3301 \\ 64,21 & 2,1804 & 5,1667 & 3,3652 \\ 66,14 & 1,2472 & 1,7924 & 1,9284 \\ 67,45 & 0,2265 & 0,0759 & 0,3483 \\ 71,88 & 5,6784 & 35,406 & 8,5898 \\ 66,58 & 0,7743 & 0,6206 & 1,2054 \\ 66,47 & 0,658 & 0,535 & 0,6581\end{array}$

\section{Kesimpulan}

Berdasarkan hasil analisa data dan pembahasan tim memperoleh beberapa kesimpulan, bahwa hasil pengembangan produk FSM menggunakan model 4-D diperoleh hasil validasi ahli rata-rata sebesar 3,667 yang termasuk kategori cukup valid, sedangkan hasil uji coba produk tingkat error akurasi ratarata mencapai 0,217 . Kemudian berdasarkan hasil simulasi diketahui bahwa metode terbaik yang digunakan dalam prediksi data IPM NTB tahun 2018 adalah metode Holt dengan hasil prediksi tahun 2018 sebesar 67,4516 dengan MAD, MSE dan MAPE berturut-turut sebesar 0,22654; 0,075955 dan 0,34829. Sedangkan model matematika yang dikonstruksi menggunakan metode Newton-Gregory berderajat 7 berdasarkan Persamaan 2,

$$
P_{7}(x)=0.0016 \mathrm{x}^{7}-0.038 \mathrm{x}^{6}+0.358 \mathrm{x}^{5}-1.689 \mathrm{x}^{4}+4.124 \mathrm{x}^{3}-4.924 \mathrm{x}^{2}+3.146 \mathrm{x}+61.16
$$

Selanjutnya berdasarkan hasil penelitian ini, maka pada makalah ini diberikan beberapa saran untuk penelitian lanjutan, agar menambah metode forcasting yang lebih luas agar diperoleh wawasan tambahan dalam menentukan kebijakan yang tepat dalam menentukan hasil forecasting data yang sering digunakan oleh pemerintah atau Badan Pusat Statistika (BPS), dan digunakan data lebih banyak lagi, misalnya data penduduk, data kesehatan, data kemiskinan, data ekonomi dan sebagainya, agar diperoleh hasil training data yang majemuk dan bervariasi.

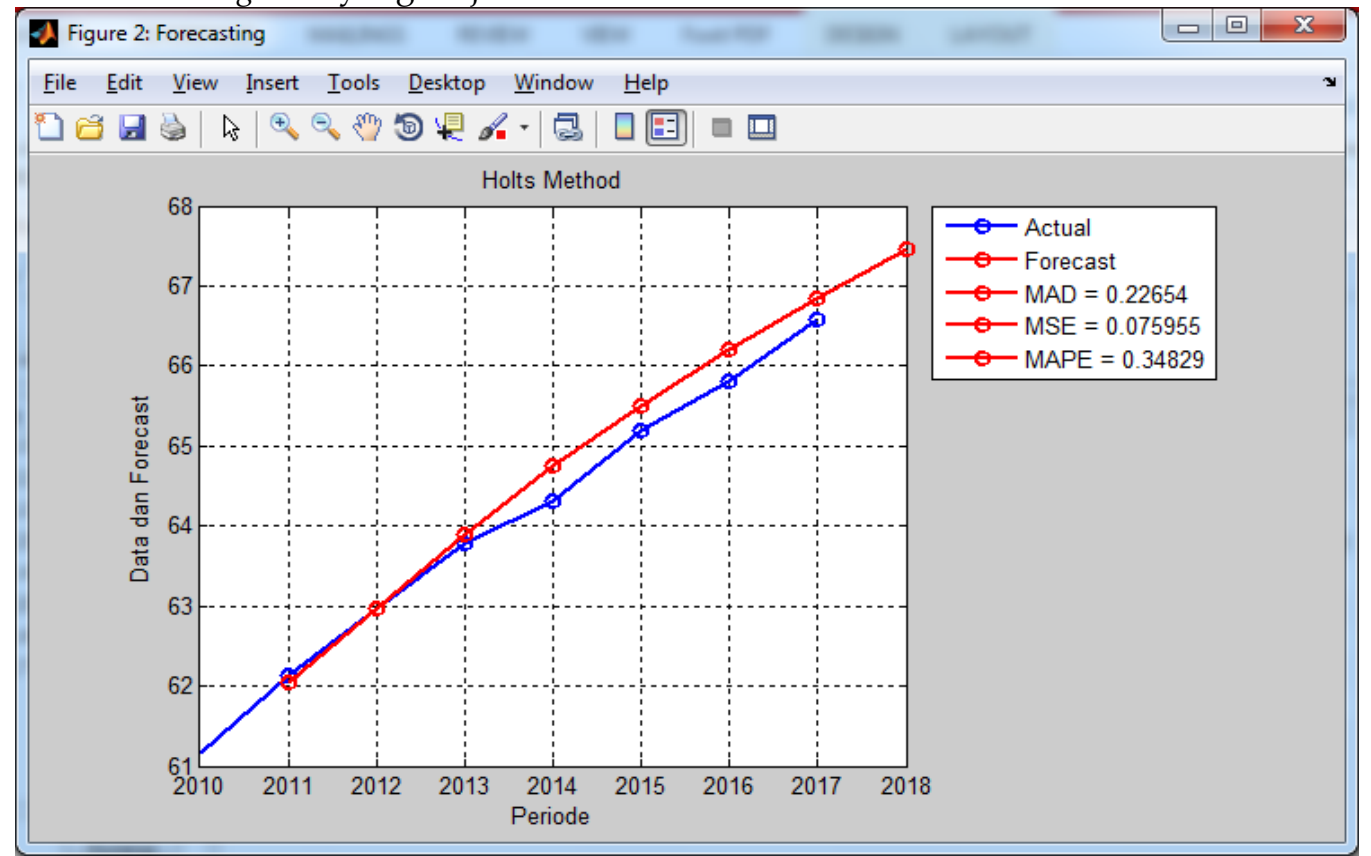

Gambar 6. Tingkat akurasi hasil simulasi metode Holt 


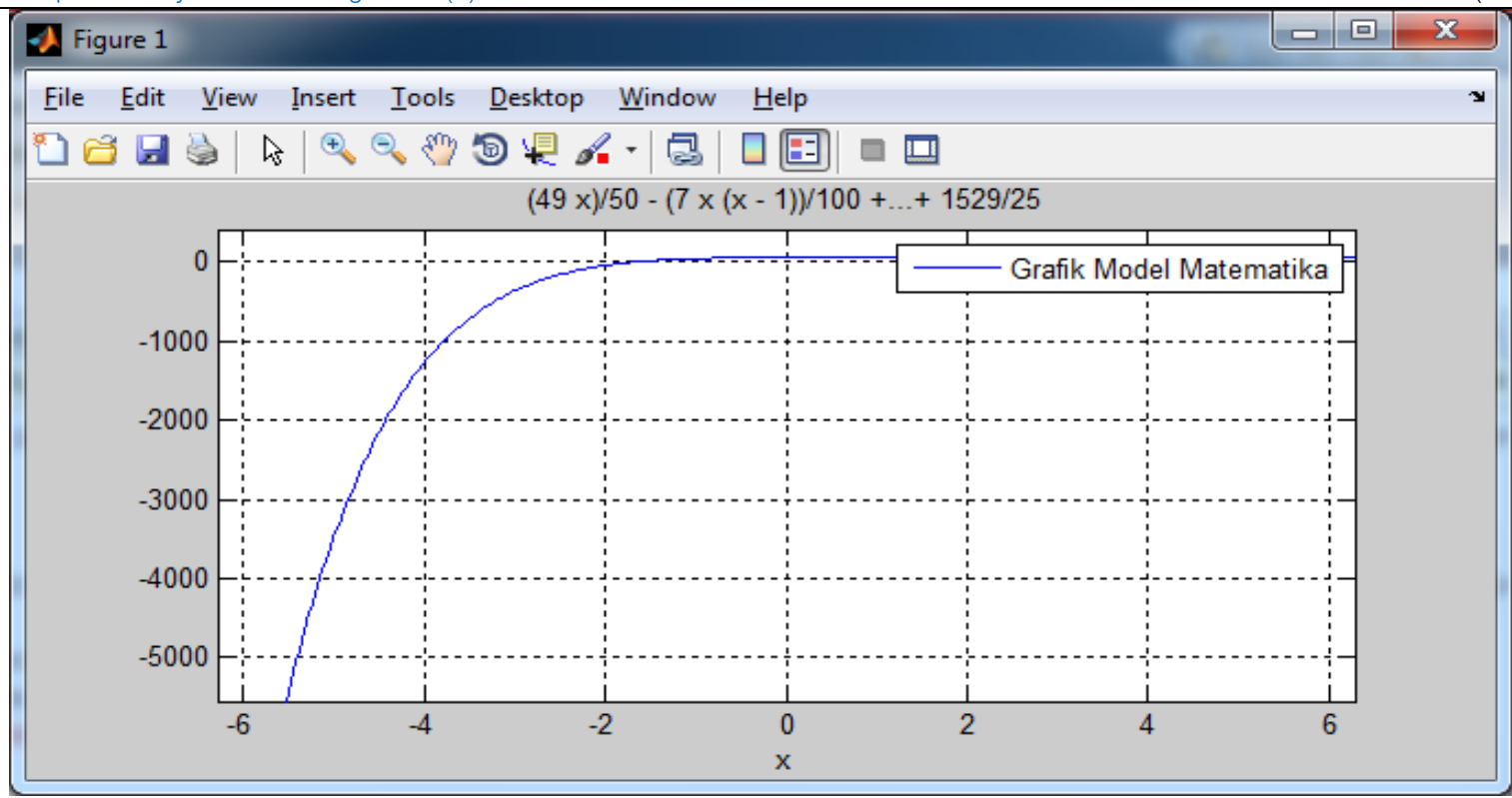

Gambar 7. Grafik model matematika

\section{Ucapan Terima Kasih}

Tim peneliti mengucapkan terima kasih kepada LPPM Universitas Islam Negeri (UIN) Mataram yang telah mendanai kegiatan penelitian ini. Kemudian kepada tim laboran dari Laboratorium Matematika UIN Mataram yang telah banyak membantu dalam konstruksi algoritma dan GUI Matlab dari FSM sehingga simulasi data sangat baik. Terakhir, kepada para validator terima kasih atas masukan untuk perbaikan tampilan GUI, semoga hasil penelitian ini akan bermanfaat untuk orang banyak.

\section{Referensi}

Andriani, Y., Silitonga, H., \& Wanto, A. (2018). Analisis Jaringan Syaraf Tiruan untuk prediksi volume ekspor dan impor migas di Indonesia. Register: Jurnal Ilmiah Teknologi Sistem Informasi, 4(1), 30-40.

Ayub, A. F., Sembok, T. M., \& Luan, W. S. (2008). Teaching and Learning Calculus Using Computer. Retrieved from http://atcm.mathandtech.org/ep2008/papers_full/2412008_15028.pdf

Guangpu, L., \& Yuchun, G. (2012). The Application of MATLAB in Communication Theory. Procedia Engineering, 29, 321-324.

Irawan, M. I., Syaharuddin, S., Utomo, D. B., \& Rukmi, A. M. (2013). Intelligent Irrigation Water Requirement System Based on Artificial Neural Networks and Profit Optimization for Planning Time Decision Making of Crops in Lombok Island. Journal of Theoretical and Applied Information Technology, 58(3), 657-671.

Sudarsono, A. (2016). Jaringan Syaraf Tiruan Untuk Memprediksi Laju Pertumbuhan Penduduk Menggunakan Metode Bacpropagation (Studi Kasus Di Kota Bengkulu). Jurnal Media Infotama, 12(1), 61-69.

Sugiono, S. (2016). Metode Penelitian Kuantitatif, Kualitatif, dan R \& D. Bandung: Alfabeta.

Suhaedi, S., Febriana, E., Syaharuddin, S., \& Negara, H. (2017). Ann Back Propagation For Forecasting And Simulation Hydroclimatology Data. International Journal Of Scientific \& Technology Research, 6(10), 110-114.

Surihadi, A. A. (2009). Penerapan Metode Single Moving Average Dan Exponential Smoothing Dalam Peramalan Permintaan Produk Meubel Jenis Coffee Table Pada Java Furniture Klaten. Surakarta: Universitas Sebelas Maret.

Suryani, I., \& Wahono, R. S. (2015). Penerapan Exponential Smoothing untuk Transformasi Data dalam Meningkatkan Akurasi Neural Network pada Prediksi Harga Emas. Journal of Intelligent Systems, $1(2), 67-75$.

Syaharuddin, S., Negara, H. R., Mandailina, V., \& Sucipto, L. (2017). Calculus Problem Solution And Simulation Using GUI Of Matlab. International Journal of Scientific \& Technology Research, 6(9), 275279. 
Thiagarajan, S., Semmel, M., \& Semmel, D. (1974). Instructional development for training teachers of exceptional children: A sourcebook. Bloomington: Indiana University. Retrieved from https://files.eric.ed.gov/fulltext/ED090725.pdf 